\title{
Use of MgO to promote the oxyethylation reaction of lauryl alcohol
}

\author{
Agnieszka Pilarska1, Marek Lukosek ${ }^{3}$, Katarzyna Siwińska-Stefańska ${ }^{1}$, Krzysztof Pilarski², \\ Teofil Jesionowski ${ }^{1, *}$ \\ ${ }^{1}$ Poznan University of Technology, Institute of Chemical Technology and Engineering, Faculty of Chemical Technology, \\ M. Skłodowskiej-Curie 2, 60-965 Poznań, Poland \\ ${ }^{2}$ Poznan University of Life Science, Institute of Biosystems Engineering, Faculty of Agriculture and Bioengineering, Wojska \\ Polskiego 50, 60-637 Poznań, Poland \\ ${ }^{3}$ Institute of Heavy Organic Synthesis "BLACHOWNIA”, Energetyków 9, 47-225 Kędzierzyn-Koźle, Poland \\ "Corresponding author: e-mail: Teofil.Jesionowski@put.poznan.pl
}

\begin{abstract}
Synthesis of magnesium hydroxide was performed by the precipitation method with the use of magnesium sulfate and sodium hydroxide. The influence of temperature and ratio of reagents was studied. Magnesium hydroxides, and the magnesium oxides obtained from them by thermal decomposition, were analyzed to determine their bulk density, polydispersity and particle size. The magnesium oxide with the largest surface area was tested as a catalyst in the oxyethylation of lauryl alcohol, and shown to be selective but poorly reactive in comparison with commercially available catalysts. Further studies are needed to improve its reactivity.
\end{abstract}

Keywords: magnesium hydroxide and oxide, precipitation, dispersive and structural properties, oxyethylation, catalytic activity.

\section{INTRODUCTION}

Magnesium hydroxide is one of the important precursors of magnesium oxide. It has also been successfully used as a neutralizer of acidic pollutants of water and gas, and as a bactericide ${ }^{1}$. Its non-toxicity and high thermal stability make it suitable as an agent for reducing the flammability of polymer materials. The vast scientific and technological literature on the use of magnesium hydroxide as a new generation flame retardant provides evidence of the growing interest in this inorganic filler ${ }^{2,3}$.

Magnesium oxide has recently become a subject of considerable interest because of its unique properties. $\mathrm{MgO}$ has found wide applications as a catalyst, as a refractory material, and in optically transparent ceramics windows ${ }^{4-6}$. In catalysis, magnesium oxide with large surface area and nanocrystalline structure has promising applications as a catalyst support for certain reactions, such as dry reforming, dehydrohalogenation, and oxidative dehydrogenation of butane ${ }^{7-9}$. The high efficiency of nanoparticle oxides results not only from their high surface area, but also from a high concentration of low-coordinated sites and structural defects on their surface ${ }^{\mathbf{1 0}}$. As the particle size is scaled down to few nanometers, the constituting atoms are set in highly defective coordination environments. Most of the atoms have unfilled valencies and reside at the surface. Depending on preparation methods, $\mathrm{MgO}$ can exhibit quite different reactivity toward adsorbed chemicals. Therefore, a large surface area material having the most defect sites per unit area should be of interest as a catalyst and catalyst support.

Coluccia and Tench proposed a surface model for $\mathrm{MgO}^{11}$ according to which there are several $\mathrm{Mg}-\mathrm{O}$ ion pairs of different coordination numbers. The ion pairs of low coordination numbers are set at corners, edges, or high Miller index surfaces of the plane. Different basic sites generated by increasing the pretreatment temperature appear to correspond to the ion pairs of different coordination numbers. However, the correspondence between the catalytically active sites for different reaction types and the coordination number of the ion pairs has not yet been definitely confirmed.

This paper presents the results of an investigation of $\mathrm{Mg}(\mathrm{OH})_{2}$ and $\mathrm{MgO}$ synthesis by the precipitation method with the use of magnesium sulfate. The effect of selected process conditions on the physicochemical properties of magnesium hydroxide and oxide was analyzed. The magnesium oxide obtained, which had good dispersive properties and large surface area, was tested as a catalyst in the oxyethylation of lauryl alcohol. These tests were motivated by the need for effective, specific catalytic compounds, homogeneous or heterogeneous, to enable such reactions. The direct introduction of ethylene oxide is not possible; it requires the use of a catalyst to activate the substrate or the ethylene oxide itself ${ }^{\mathbf{1 2}}$. A potential catalyst must be easily removable from the product, so that it does not become an impurity. The calcium-based catalysts described in the literature have long induction times, which makes them less desirable for industrial applications ${ }^{13}$. Keeping the reagents, particularly ethylene oxide, at high temperature and raised pressure for a long time may lead to an uncontrolled reaction path. Moreover, oxyethylation reactions are important in industry, among other things because they can produce non-toxic, environmentally friendly surfactants ${ }^{14}$.

Magnesium oxide satisfies all of the conditions for an effective catalyst. According to literature reports, as a catalyst it is active, selective (in view of the defective microstructure and the existence of acid-base sites), high-yielding and non-toxic, with a large surface $\operatorname{area}^{7-9,15,16}$.

\section{EXPERIMENTAL}

\section{Synthesis of $\operatorname{Mg}(\mathrm{OH})_{2}$ and $\mathrm{MgO}$}

The substrates used were hydrated magnesium sulfate (analytical grade) and sodium hydroxide (also of analytical grade) in the form of solutions of appropriate concentrations, produced by POCh SA, Poland. Precipitation of magnesium hydroxide was performed in a reactor of $500 \mathrm{~cm}^{3}$ capacity equipped with a high-speed propeller 
stirrer (Eurostar Digital IKA-Werke GmbH, Germany, $1800 \mathrm{rpm}$ ). The reaction system was thermostated in a water bath made by Julabo Labortechnik $\mathrm{GmbH}$, Germany. The process temperatures used were 20, 40, 60 , and $80^{\circ} \mathrm{C}$. The reagents at appropriate concentrations were dosed simultaneously into the water system by means of a peristaltic pump (ISM 833A, Ismatec, Switzerland). Use of the pump permitted the maintenance of a constant substrate supply rate of $2.3 \mathrm{~cm}^{3} / \mathrm{min}$. The concentration of the magnesium sulfate solutions was $5 \%$. The quantity of sodium hydroxide in the solutions was determined for the stoichiometric ratio (1:1) of the reagents. As the influence of excess quantities of the reagents was also to be studied, we used reaction mixtures with reagent ratios of 1.5:1, 2:1 (excess salt), and 1:1.5 (excess sodium hydroxide).

The magnesium hydroxide precipitate was filtered off, washed and dried by the convection method or by static drying at $105^{\circ} \mathrm{C}$ for $6 \mathrm{~h}$ (in a chamber drier made by Memmert). The dried intermediate product (magnesium hydroxide) was subjected to gradual calcination in an electric furnace (Controller P320 MB1, Nabertherm GmbH, Germany) at $450^{\circ} \mathrm{C}$ for $2 \mathrm{~h}$ to obtain magnesium oxide.

\section{Characterization of the catalysts}

For all magnesium hydroxide samples and $\mathrm{MgO}$, first the bulk density was determined. Bulk densities were determined using a WE-5 electromagnetic volumeter (Poland). Then the particle size distributions of the samples were determined, using a Zetasizer Nano ZS and Mastersizer 2000 (both from Malvern Instruments Ltd., UK), permitting measurements of particle diameters in ranges of $0.6-6000 \mathrm{~nm}$ (non-invasive backscattering technique - NIBS) and 0.2-2000 $\mu \mathrm{m}$ (laser diffraction technique) respectively. Cumulant analysis gives a width parameter known as the polydispersity, or the polydispersity index (PdI). In order to characterize parameters of the porous structure, nitrogen adsorption/desorption isotherms at $77 \mathrm{~K}$ and surface area $\left(\mathrm{A}_{\mathrm{BET}}\right)$, pore volume $\left(\mathrm{V}_{\mathrm{p}}\right)$ and average pore size $\left(\mathrm{S}_{\mathrm{p}}\right)$ were determined using an ASAP 2020 (Accelerated Surface Area and Porosimetry) instrument (Micromeritics Instrument Co., USA). The surface area was determined by the multipoint BET method using the adsorption data under relative pressure $\left(\mathrm{p} / \mathrm{p}_{0}\right)$. The BJH algorithm was applied to determine the pore volume and the average pore size.

\section{Catalytic activity of $\mathrm{MgO}$}

The catalytic activity of magnesium oxide in the oxyethylation of lauryl alcohol was tested in a pressure system. The process of oxyethylation was carried out in a pressure reactor $2 \mathrm{dm}^{3}$ in capacity (Autoclave Engineers, USA), made of acid-resistant steel. The reagents used were $98 \%$ pure lauryl alcohol (Sigma-Aldrich, Germany), and ethylene oxide from ChemoGas NV Belgium, of minimum purity $99.9 \%$.

Syntheses of the oxyethylation of lauryl alcohol were carried out using the produced $\mathrm{MgO}$ as a catalyst, and using industrial catalysts for comparison purposes: a calcium catalyst (K-4/XII-O, no. 8/06, ICSO Blachownia, Poland) and $\mathrm{NaOH}$ (Sigma-Aldrich, Germany). Identical parameters were preset for all syntheses performed, as listed in Table 1.
Table 1. Preset parameters for the process of oxyethylation of lauryl alcohol

\begin{tabular}{|l|c|}
\hline Name of substrate & lauryl alcohol \\
\hline Mass of substrate used & $300 \mathrm{~g} \mathrm{(1.5} \mathrm{mol})$ \\
\hline Molar weight of substrate & $198 \mathrm{~g} / \mathrm{mol}$ \\
\hline $\begin{array}{l}\text { Average degree of } \\
\text { oxyethylation }\end{array}$ & 3 \\
\hline Catalyst & $\mathrm{MgO}$ \\
\hline Mass of catalyst used & $1.25 \mathrm{~g}(0.25 \%$ product $)$ \\
\hline $\begin{array}{l}\text { Mass of ethylene oxide } \\
\text { (assumed) }\end{array}$ & $200 \mathrm{~g} \mathrm{(4.5} \mathrm{mol)}$ \\
\hline Synthesis temperature & $185^{\circ} \mathrm{C} \pm 5^{\circ} \mathrm{C}$ \\
\hline Synthesis pressure, max. & $400 \mathrm{kPa}$ \\
\hline Synthesis pressure, min. & $300 \mathrm{kPa}$ \\
\hline Time of heating after synthesis & $60 \mathrm{~min}$ \\
\hline
\end{tabular}

First the reactor was charged with $300 \mathrm{~g}$ of hydrophobic substrate and a catalyst in a quantity of $0.25 \%$ with respect to the product mass. After increasing the reactor temperature to $185^{\circ} \mathrm{C}$, automatic dosing of ethylene oxide was commenced. Introduction of ethylene oxide in small doses of less than 20 grams is strongly dependent on the pressure (upper and lower) and temperature. Each subsequent portion of ethylene oxide was introduced into the reaction environment only when the pressure in the reactor dropped below a given value (lower pressure) and its temperature was within the preset range.

The fractional composition of the oxyethylates obtained was established using gas chromatography (GC). The samples studied were diluted in an appropriate solvent and the solution was injected into a chromatograph (Hewlett Packard, USA, model 5890, series 2). The column used was a high-temperature Ultra 2 type, 10 $\mathrm{m}$ in length and $0.25 \mathrm{~mm}$ in diameter.

The fractional composition of the oxyethylates obtained was established using GC/FID chromatography. This method is often found in the literature, and is used for determining the fractional composition of oxyethylates of fatty alcohols, particularly in comparing catalysts of oxyethylation processes ${ }^{17-21}$.

The HP 6890 GC gas chromatograph used is equipped with a "split/splitless" injector, a flame ionization detector (FID) and a Hewlett-Packard computer workstation. Chromatographic separation of the analyzed components was obtained using a capillary chromatographic column made of fused silica, $15 \mathrm{~m}$ in length and $0.32 \mathrm{~mm}$ in internal diameter, filled with a methyl phenyl silicone stationary phase, type ZB-5HT (or ULTRA 2) with a film thickness of $0.1 \mu \mathrm{m}$. The conditions of analysis were as follows: (i) furnace temperature program: $120^{\circ} \mathrm{C}(1 \mathrm{~min}) ; 15^{\circ} \mathrm{C} / \mathrm{min} ; 380^{\circ} \mathrm{C}(10 \mathrm{~min})$; (ii) injector temperature: $360^{\circ} \mathrm{C}$; (iii) detector temperature: $380^{\circ} \mathrm{C}$; (iv) gas flow rate through column: $2 \mathrm{~cm}^{3} / \mathrm{min}$ (argon); (v) stream split: 70:1; (vi) quantity of sample injected (manually): $0.3 \mu \mathrm{g}$.

The tested samples were diluted in an appropriate media, and the solution was then injected into the chromatograph. The separation temperature was programmed in the range $100-360^{\circ} \mathrm{C}$, the temperature of the flame ionization detector being $380^{\circ} \mathrm{C}$. The method is based on the principle that, when the chromatogram is obtained, the areas of individual peaks are measured and summed. The total sum of the areas is taken to be $100 \%$. Assuming that all components in the sample are volatile and are visible on the chromatogram, the 
area of each peak relative to the total area of all peaks corresponds to the percentage content of the analyzed substances in the sample.

\section{RESULTS AND DISCUSSION}

\section{Dispersive properties of $\mathrm{Mg}\left(\mathrm{OH}_{2}\right)$ samples}

To determine the conditions enabling the synthesis of $\mathrm{Mg}(\mathrm{OH})_{2}$ and $\mathrm{MgO}$ samples with optimum properties, the influence of such parameters as temperature and quantitative ratio of reagents was tested.

Table 2 contains the dispersive parameters of magnesium hydroxide precipitated at a rate of $2.3 \mathrm{~cm}^{3} / \mathrm{min}$, at process temperatures of $20,40,60$ and $80^{\circ} \mathrm{C}$. Moreover, magnesium hydroxide was precipitated at a stoichiometric ratio of reagents (1:1) and at ratios of 1.5:1, 2:1 (excess magnesium sulfate), and 1:1.5 (excess $\mathrm{NaOH}$ ).

The highest temperature of $80^{\circ} \mathrm{C}$ produces the best morphological and dispersive properties of the final magnesium hydroxide. Sample 4A precipitated at the stoichiometric ratio of reagents was characterized by a very low bulk density of $68 \mathrm{~g} / \mathrm{dm}^{3}$. The diameter range of the particles in this sample was 106-459 nm. The product obtained with an excess of sodium hydroxide (sample 5A) had much poorer parameters than sample 4A. Its bulk density was $367 \mathrm{~g} / \mathrm{dm}^{3}$, while its polydispersity index (0.852) and the size of its particles in the micrometric range indicate a significant tendency to agglomeration. On the other hand, sample $6 \mathrm{~A}$ obtained with an excess of magnesium sulfate $(1.5: 1)$ and at a temperature of $80^{\circ} \mathrm{C}$ exhibited much better parameters. In fact, this material had the best parameters out of all the samples obtained. The particle size distribution of this sample (Fig. 1) shows two bands. The first one covers diameters from 28 to $79 \mathrm{~nm}$, and the maximum volume contribution of $21.3 \%$ comes from particles $59 \mathrm{~nm}$ in diameter. The presence of this band testifies to the high dispersion of particles in sample 6A. The second band evidenced the presence of agglomerates whose diameter reached $2300 \mathrm{~nm}$, but which had a low volume contribution.

Particle agglomeration can take place at every stage during liquid-phase preparation, such as nucleation and growth and the washing and drying of precipitates. Several representative theories have been proposed, including some based on crystal bridge, capillary pressure, hydrogen bond and chemical bond formation ${ }^{21,22}$. Figure 2 illustrates the proposed mechanism of agglomerate formation.

The effect of calcination on the dispersive and the structural properties of magnesium oxide samples

The bulk densities of the magnesium oxide samples obtained were lower than those of the corresponding magnesium hydroxides, which is explained first of all by mass loss during calcination. The polydispersity

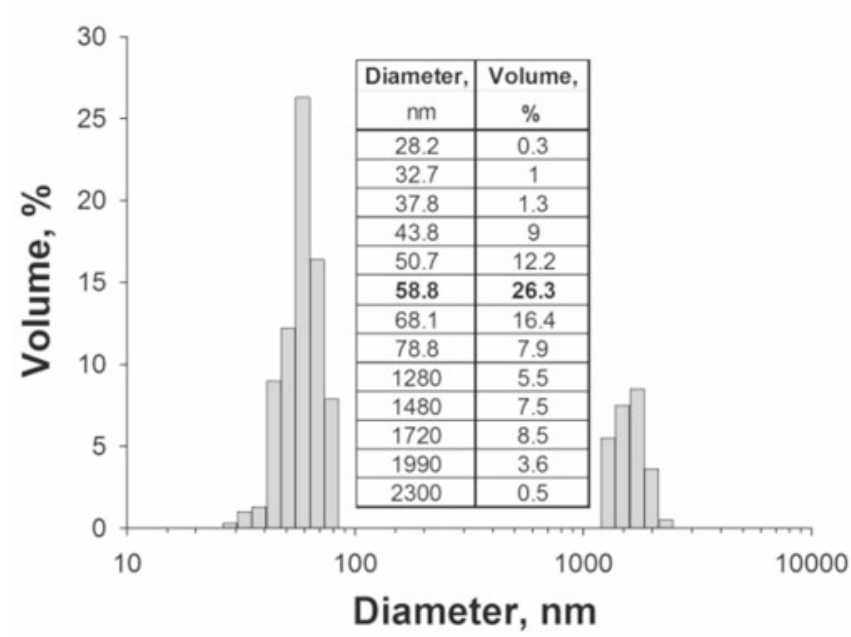

Figure 1. Particle size distribution (Zetasizer Nano ZS) of magnesium hydroxide (sample 6A), precipitated with excess magnesium sulfate at $80^{\circ} \mathrm{C}$

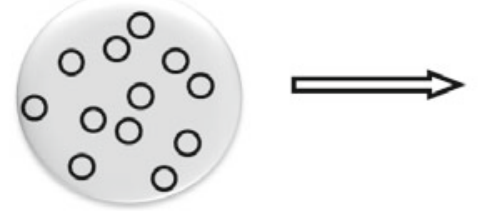

primary particles

$\mathrm{d}<100 \mathrm{~nm}$

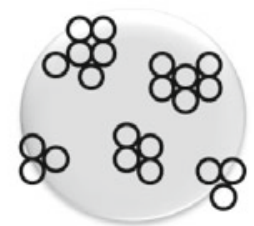

aggregates

d $>100 \mathrm{~nm}$
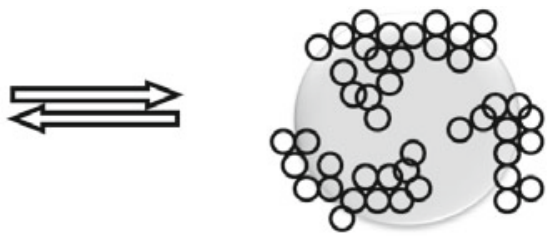

agglomerates

$\mathrm{d}>1000 \mathrm{~nm}$

Figure 2. Mechanism of aggregate and agglomerate structure formation

Table 2. Physicochemical properties of $\mathrm{Mg}(\mathrm{OH})_{2}$ precipitated with different ratios of reagents at $20,40,60$ and $80^{\circ} \mathrm{C}$

\begin{tabular}{|c|c|c|c|c|c|c|c|c|}
\hline \multirow{3}{*}{$\begin{array}{l}\text { Sample } \\
\text { No. }\end{array}$} & \multicolumn{2}{|c|}{ Precipitation process conditions } & \multicolumn{6}{|c|}{ Physicochemical and dispersive properties } \\
\hline & \multirow{2}{*}{$\begin{array}{l}\text { Temperature, } \\
{ }^{\circ} \mathrm{C}\end{array}$} & \multirow{2}{*}{$\begin{array}{l}\text { Salt } / \mathrm{NaOH} \\
\text { ratio }\end{array}$} & \multirow{2}{*}{$\begin{array}{c}\text { Bulk } \\
\text { density, } \\
\text { g/dm }\end{array}$} & \multirow{2}{*}{$\begin{array}{l}\text { Polydispersity } \\
\text { index }\end{array}$} & \multirow{2}{*}{$\begin{array}{c}\text { Diameter range } \\
\text { from Zetasizer } \\
\text { Nano ZS, nm }\end{array}$} & \multicolumn{3}{|c|}{$\begin{array}{c}\text { Particle size } \\
\text { from Mastersizer 2000, } \mu \mathrm{m}\end{array}$} \\
\hline & & & & & & $d(0.1)$ & $d(0.5)$ & $d(0.9)$ \\
\hline $1 \mathrm{~A}$ & 20 & \multirow{4}{*}{$1: 1$} & 171 & 0.180 & 122-396 & 2.74 & 7.19 & 22.56 \\
\hline $2 \mathrm{~A}$ & 40 & & 188 & 0.385 & $\begin{array}{r}164-1110 \\
1280-5560\end{array}$ & 2.00 & 4.70 & 28.04 \\
\hline $3 \mathrm{~A}$ & 60 & & 209 & 0.484 & $142-531$ & 2.48 & 9.42 & 49.62 \\
\hline $4 \mathrm{~A}$ & \multirow{4}{*}{80} & & 68 & 0.214 & $106-459$ & 2.69 & 6.30 & 26.73 \\
\hline $5 \mathrm{~A}$ & & $1: 1.5$ & 367 & 0.852 & $122-531$ & 3.52 & 20.38 & 61.72 \\
\hline $6 \mathrm{~A}$ & & $1.5: 1$ & 130 & 0.245 & $\begin{array}{c}28-79 \\
1280-2300\end{array}$ & 1.83 & 3.73 & 9.83 \\
\hline $7 A$ & & $2: 1$ & 132 & 0.394 & 342-955 & 1.95 & 4.41 & 20.40 \\
\hline
\end{tabular}


Table 3. Physicochemical properties of selected $\mathrm{MgO}$ obtained with the use of $5 \%$ solution of magnesium sulfate at $80^{\circ} \mathrm{C}$

\begin{tabular}{|c|c|c|c|c|c|c|c|c|c|}
\hline \multirow{3}{*}{$\begin{array}{l}\text { Sample } \\
\text { No. }\end{array}$} & \multicolumn{3}{|c|}{ Precipitation process conditions } & \multicolumn{6}{|c|}{ Physicochemical and dispersive properties } \\
\hline & \multirow{2}{*}{$\begin{array}{c}\text { Temperature, } \\
{ }^{\circ} \mathrm{C}\end{array}$} & \multirow{2}{*}{$\begin{array}{l}\text { Concentration } \\
\mathrm{MgSO}_{4}, \%\end{array}$} & \multirow{2}{*}{$\begin{array}{l}\text { Salt } / \mathrm{NaOH} \\
\quad \text { ratio }\end{array}$} & \multirow{2}{*}{$\begin{array}{l}\text { Bulk } \\
\text { density, } \\
\mathrm{g} / \mathrm{cm}^{3}\end{array}$} & \multirow{2}{*}{$\begin{array}{c}\text { Polydispersity } \\
\text { index }\end{array}$} & \multirow{2}{*}{$\begin{array}{l}\text { Diameter } \\
\text { range } \\
\text { from } \\
\text { Zetasizer } \\
\text { Nano ZS, nm }\end{array}$} & \multicolumn{3}{|c|}{$\begin{array}{c}\text { Particle size } \\
\text { from Mastersizer } 2000, \mu \mathrm{m}\end{array}$} \\
\hline & & & & & & & $\mathrm{d}(0.1)$ & $\mathrm{d}(0.5)$ & $\mathrm{d}(0.9)$ \\
\hline 4B & \multirow{4}{*}{80} & \multirow{4}{*}{5} & $1: 1$ & 49 & 0.280 & $531-670$ & 3.34 & 8.45 & 32.51 \\
\hline $5 B$ & & & $1: 1.5$ & 309 & 0.950 & $122-5560$ & 3.52 & 20.38 & 61.72 \\
\hline 6B & & & $1.5: 1$ & 110 & 0.286 & $122-3580$ & 1.86 & 4.08 & 24.50 \\
\hline 7B & & & $2: 1$ & 98 & 0.426 & 190-2670 & 1.95 & 4.41 & 20.40 \\
\hline
\end{tabular}

indices determined for the magnesium oxide samples are higher than those of the corresponding hydroxides, which indicates a deterioration in homogeneity. Higher polydispersity indices imply the presence of particles with greater diameters (see Table 3).

The presence of these attests to the occurrence of particle agglomeration during calcination of magnesium hydroxides. The undesirable changes are interpreted as a result of the process of agglomeration taking place on increase in temperature. Changes in the morphology and dispersion of the samples can be important when considering their application as catalysts.

Analysis of the structural properties of the samples studied confirms the effect of calcination on the microstructure of $\mathrm{Mg}(\mathrm{OH})_{2}$ (Table 4). $\mathrm{MgO}$ samples obtained as a result of calcination had pores of sizes smaller than or comparable to those in the corresponding magnesium hydroxide samples, indicating the mesoporous character of the material, and greater pore volume. These textural changes determined the surface area of the $\mathrm{MgO}$ samples, which were generally larger than those in the corresponding magnesium hydroxide samples. In his $\operatorname{paper}^{\mathbf{2 3}}$ on structural changes taking place upon decomposition of nanocrystalline $\mathrm{Mg}(\mathrm{OH})_{2}$ to $\mathrm{MgO}$, Melgunov has reported that in the precipitated $\mathrm{Mg}(\mathrm{OH})_{2}$ crystals, the surface density of $\mathrm{Mg}$ atoms in the face is higher than in $\mathrm{MgO}$.

Magnesium hydroxide synthesis by precipitation from magnesium salt solutions, in the optimum conditions established for the process, offers the possibility of obtaining products with large surface areas. According to

Table 4. Porous structure parameters of selected magnesium hydroxide samples and their calcinates obtained using a $5 \%$ solution of magnesium sulfate at $80^{\circ} \mathrm{C}$

\begin{tabular}{|l|c|c|c|}
\hline $\begin{array}{l}\text { Sample } \\
\text { No. }\end{array}$ & $\begin{array}{c}\text { BET surface } \\
\text { area, } \\
\mathrm{m}^{2} / \mathrm{g}\end{array}$ & $\begin{array}{c}\text { Total pore } \\
\text { volume, } \\
\mathrm{cm}^{3} / \mathrm{g}\end{array}$ & $\begin{array}{c}\text { Mean size of } \\
\text { pores, } \\
\mathrm{nm}\end{array}$ \\
\hline 4A & 110 & 0.30 & 19 \\
\hline 4B & 156 & 0.42 & 15 \\
\hline $5 \mathrm{~A}$ & 45 & 0.20 & 12 \\
\hline 5B & 68 & 0.30 & 10 \\
\hline $6 \mathrm{~A}$ & 91 & 0.62 & 27 \\
\hline $6 \mathrm{~B}$ & 269 & 0.92 & 13 \\
\hline 7A & 60 & 0.50 & 34 \\
\hline 7B & 76 & 0.66 & 32 \\
\hline
\end{tabular}

literature data ${ }^{24,25}$, the use of magnesium sulfate, besides magnesium nitrate and magnesium chloride, is most favorable for the formation of magnesium hydroxide and hence also magnesium oxide - with small particles and large surface areas. Most probably the reason is the good water solubility of this salt, which affects the character of the nucleation. It has been proved that the oxides obtained at high temperatures show greater catalytic and adsorption activity ${ }^{\mathbf{2 6}}$.

Sample 6B, with its large surface area of $269 \mathrm{~m}^{2} / \mathrm{g}$ and high contribution of nanometric particles, was selected as the best for catalytic tests. WAXS ${ }^{27}$ and TG/DTA ${ }^{28}$ studies confirmed the purity of this sample and its well-developed crystalline structure with characteristics of periclase.

\section{Catalytic evaluation of $\mathrm{MgO}$}

The catalytic activity of magnesium oxide (sample 6B) was tested in the oxyethylation of lauryl alcohol. The catalyst was found to be relatively active. A distinct decrease in the pressure observed each time after introduction of ethylene oxide into the reactor provided evidence of the progress of the reaction. The test was successful as the entire amount of ethylene oxide was dosed, but the process was slow. The time of reaction and the rate of reaction are given in Table 5, where the corresponding data for two commercial catalysts are also shown.

According to the results obtained, the use of $\mathrm{MgO}$ in unmodified form (sample 6A) as a catalyst is rather ineffective. The reaction initiated by magnesium oxide is very slow, and its most probable mechanism is shown in Figure 3.

It is highly probable that the hydrophobic substrate (lauryl alcohol) connects with ethylene oxide (oxirane) and magnesium oxide to make magnesium alcoholate (laurynate) (step I). The subsequent oxirane molecules (step II), attached in the reaction of oxyethylation, coordinate the formation of the oxyethylated product. One of the two electron pairs coordinates to magnesium, taking advantage of the weak acidic properties of that metal. As a result of complex formation, the positive charge on the carbon atoms of oxirane increases. Because of the

Table 5. Lauryl alcohol oxyethylation over different catalysts (synthesis temperature $185^{\circ} \mathrm{C}$, mean degree of oxyethylation $\mathrm{N}_{\mathrm{av}}=3$ )

\begin{tabular}{|l|c|c|c|c|c|}
\hline $\begin{array}{l}\text { Sample } \\
\text { No. }\end{array}$ & Commercial catalyst & $\begin{array}{c}\text { Catalyst concentration, } \\
\%\end{array}$ & $\begin{array}{c}\text { Reaction time, } \\
\min \end{array}$ & $\begin{array}{c}\text { Amount of EO introduced relative to the preset value, } \\
\%\end{array}$ & $\begin{array}{c}\mathrm{V}_{\mathrm{av}}, \\
\mathrm{mol} / \mathrm{mol} \cdot \mathrm{h}\end{array}$ \\
\hline $6 \mathrm{~B}$ & - & 0.50 & 88 & 100 & 2.05 \\
\hline- & $\mathrm{K}-4 / \mathrm{XII}-\mathrm{O}$ (calcium) & 0.30 & 46 & 100 & 3.97 \\
\hline- & $\mathrm{NaOH}$ & 0.10 & 21 & 100 & 8.70 \\
\hline
\end{tabular}

$\mathrm{N}_{\mathrm{av}}$ - average degree of oxyethylation, denoting the average number of moles of ethylene oxide per mole of starting material; $\mathrm{V}_{\mathrm{av}}-$ average rate of the oxyethylation process, expressed as the number of moles of ethylene oxide introduced into the reaction environment per mole of starting material per hour; EO - ethylene oxide. 


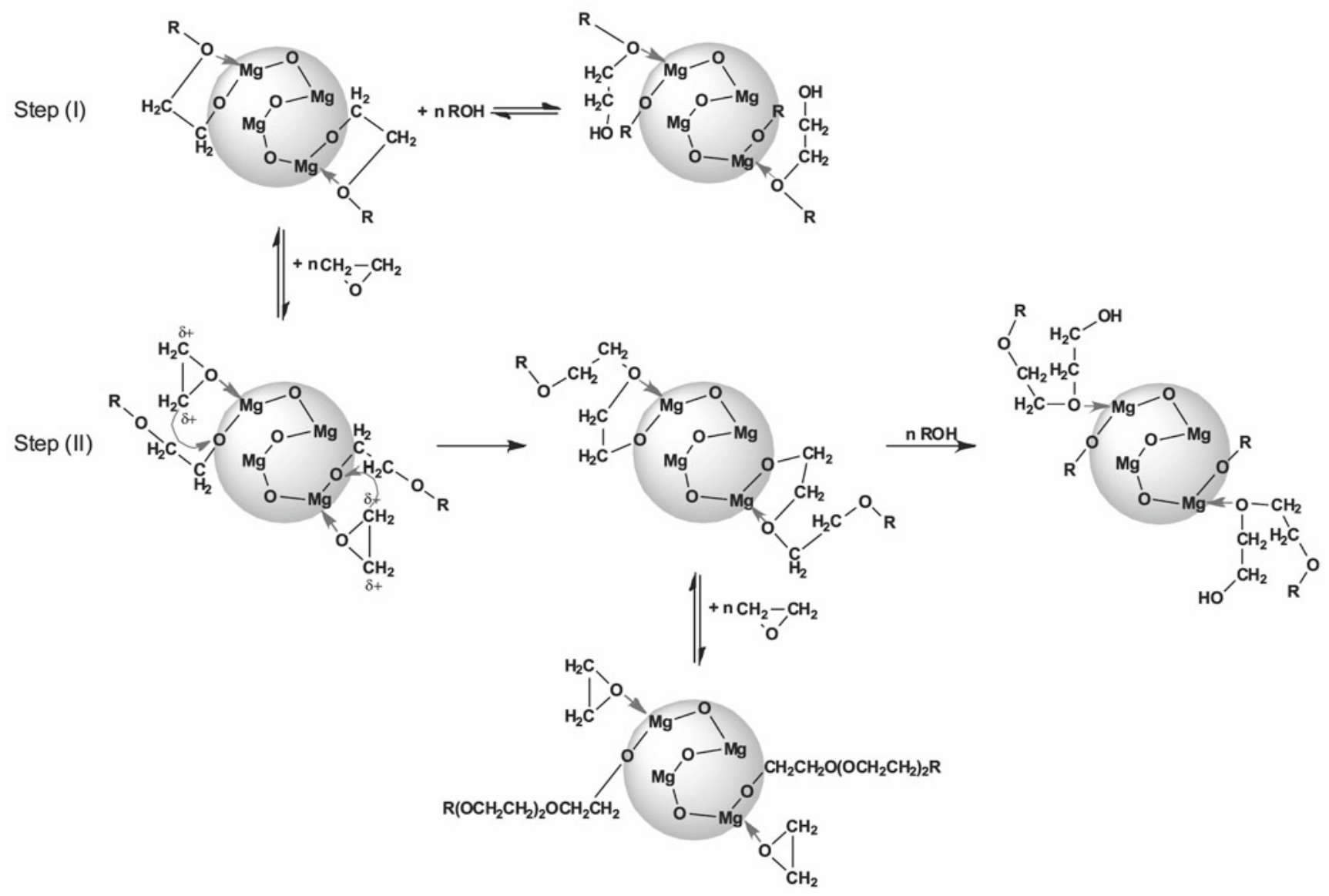

Figure 3. Mechanism of lauryl alcohol oxyethylation in the reaction catalyzed by magnesium oxide, based on ${ }^{2 y}$ (where $-\mathrm{OR}$ denotes alcoholate group of the formula $-\mathrm{OC}_{12} \mathrm{H}_{25}$, which comes from lauryl alcohol)

increase in electrophilicity, these carbon atoms become more reactive, which facilitates the carbon-oxide bonding.

The product of the oxyethylation is a mixture of a number of derivatives with different content of ethylene oxide, in which the amount of particular homologues depends on the catalyst used ${ }^{29}$. Subsequently, it is necessary to use the notion of mean oxyethylation degree, providing information on which fraction has been dominant. If the catalyst is selective, a narrow distribution of homologues is obtained. With the use of the currently available catalysts, irrespective of the hydrophobic substrate, it is possible to obtain a product in which the target component makes up a maximum amount of $30 \%$ wt./wt. in the mixture of oxyethylates ${ }^{12,30}$. In our experiment the synthesis was performed with a mean degree of oxyethylation of 3 .

Consequently, the content of oxyethylated product containing three molecules of ethylene oxide was as high as $19.30 \%$ (Table 6). It should be noted, however, that a very similar percentage was also obtained for the compound with two molecules of oxirane (19.24\%), which for products of this type is a satisfactory result indicating a narrowing of the distribution of homologues. The analogous product obtained using $\mathrm{NaOH}$ (a catalyst used industrially) is found to have contents of $12.93 \%$ and $12.20 \%$ for the respective fractions. Moreover, the superior selectivity of the $\mathrm{MgO}$ catalyst compared with $\mathrm{NaOH}$ is evidenced by, as well as the narrowing of the distribution of homologues, the content of unreacted starting material. The content of the original alcohol in the product obtained using $\mathrm{MgO}$ as catalyst was $14.72 \%$, compared with $17.82 \%$ in the case of $\mathrm{NaOH}$ (Table 6).
Table 6. Distribution of homologues in the product of lauryl alcohol oxyethylation $\left(\mathrm{N}_{\mathrm{av}}=3\right)$ using $\mathrm{MgO}, \mathrm{NaOH}$ and K-4/XII-O as catalysts. GC/FID analysis

\begin{tabular}{|l|c|c|c|}
\hline \multirow{2}{*}{$\begin{array}{l}\text { Oxethylates of lauryl } \\
\text { alcohol }\end{array}$} & \multicolumn{3}{|c|}{ Tractional composition, \% } \\
\cline { 2 - 4 } & $\mathrm{MgO}$ & $\mathrm{NaOH}$ & $\begin{array}{c}\mathrm{K}-4 / \mathrm{XII} \text {-O } \\
\text { (calcium) }\end{array}$ \\
\cline { 2 - 4 } Alcohol C-12/0 & 14.72 & 17.82 & 13.01 \\
\hline $\mathrm{C}-12 / 1$ & 14.95 & 12.05 & 8.32 \\
\hline $\mathrm{C}-12 / 2$ & 19.24 & 12.20 & 14.50 \\
\hline $\mathrm{C}-12 / 3$ & 19.30 & 12.93 & 21.64 \\
\hline $\mathrm{C}-12 / 4$ & 15.01 & 10.05 & 19.91 \\
\hline $\mathrm{C}-12 / 5$ & 9.02 & 7.52 & 12.33 \\
\hline $\mathrm{C}-12 / 6$ & 4.40 & 6.88 & 6.42 \\
\hline $\mathrm{C}-12 / 7$ & 1.79 & 5.02 & 2.08 \\
\hline $\mathrm{C}-12 / 8$ & 0.63 & 4.91 & 0.89 \\
\hline $\mathrm{C}-12 / 9$ & 0.26 & 3.23 & 0.35 \\
\hline $\mathrm{C}-12 / 10$ & 0.11 & 2.12 & 0.29 \\
\hline $\mathrm{C}-12 / 11$ & 0.05 & 1.80 & 0.04 \\
\hline $\mathrm{C}-12 / 12$ & traces & 1.26 & traces \\
\hline Other components & 0.52 & 2.21 & 0.22 \\
\hline
\end{tabular}

where, for example, $\mathrm{C}-12 / 2$ denotes oxyethylate of $\mathrm{C} 12$ alcohol with 2 moles of ethylene oxide attached

Generally speaking, the oxyethylates, particularly oxyethylates of alcohols, are always a mixture of homologues with different degrees of polyoxyethylation. This results from the different reactivity of the starting material and the various homologues, which take part in parallel reactions with ethylene oxide and propagation of the oxyethylene chain. It is possible to improve the reactivity 
and obtain a narrower distribution of homologues with the use of appropriate catalysts ${ }^{31,32}$.

The lauryl alcohol oxyethylate obtained demonstrates good quality and relatively small distribution of oxyethylene homologues (narrow-fraction oxyethylates). The tested catalyst $(\mathrm{MgO}$, sample $6 \mathrm{~B})$ was shown to be selective in the process of oxyethylation, but its activity was much too low relative to that of the commercially available catalysts, which precludes its use in the present form as a technological material. The most probable explanation is that the acidic properties of magnesium are too weak and prevent realization of the process of insertion. Studies aimed at improving the catalytic behavior of $\mathrm{MgO}$ will be continued, including with the use of modifying agents - oxides of other metals (e.g. alumina) or pure metals.

\section{CONCLUSIONS}

The results of the experiments show the significant influence of experimental conditions on the properties of the final products. The product with optimum properties was obtained when the synthesis was performed at $80^{\circ} \mathrm{C}$ in the presence of an excess of the salt. The process of calcination was found to affect the dispersive properties of magnesium oxide;moreover the porous structure parameters were improved. The magnesium hydroxide samples with the best physicochemical parameters (sample 6A) contained particles with diameters of 28-79 nm and surface area (BET) of $91 \mathrm{~m}^{2} / \mathrm{g}$. The corresponding magnesium oxide (sample 6A) contained particles of greater diameter $(122-3580 \mathrm{~nm})$, and its surface area was $269 \mathrm{~m}^{2} / \mathrm{g}$. The catalyst studied proved to be selective in the oxyethylation of lauryl alcohol, but poorly reactive. Further studies are needed to improve its reactivity.

\section{ACKNOWLEDGMENTS}

This work was supported by Poznan University of Technology research grant no. 32-375/2013-DS.

\section{LITERATURE CITED}

1. Dong, C., Cairney, J., Sun, Q., Maddan, O.L., He, G. \& Deng, Y. (2010). Investigation of $\mathrm{Mg}(\mathrm{OH})_{2}$ nanoparticles as an antibacterial agent, J. Nanopart. Res. 12, 2101-2109. DOI: 10.1007/s11051-009-9769-9.

2. Chen, X., Yu, J., Guo, S., Lu, S., Luo, Z. \& He, M. (2009). Effects of magnesium hydroxide and its surface modification on crystallization and rheological behaviors of polypropylene, Polym. Compos. 30, 941-947. DOI: 10.1002/pc.20638.

3. Xiang-jian, K., Shu-hei, L. \& Jiang-ging, Z. (2008). Flame retardancy effects of surface-modified metal hydroxides on linear low density polyethylene, J. Cent. South Univ. Technol. 15, 779-785. DOI: 10.1007/s11771-008-0144-2.

4. Khor, S.F., Talib, Z.A., Daud, W.M., Sidek, H.A.A. \& $\mathrm{Ng}$, B.H. (2009). Effects of $\mathrm{MgO}$ on dielectric properties and electrical conductivity of ternary zinc magnesium phosphate glasses, J. Non-Cryst. Solids 355, 2533-2539. DOI: 10.1016/j. jnoncrysol.2009.09.010.

5. Lei, T., Ouyang, C., Tang, W., Li, L.F. \& Zhou, L.S. (2010). Preparation of $\mathrm{MgO}$ coatings on magnesium alloys for corrosion protection, Surface Coat. Technol. 204, 3798-3803. DOI: 10.1016/j.surfcoat.2010.04.060.

6. Lei, H., Dianqing, L., Yanjun, L., Evans, D.G. \& Xue, D. (2005). Influence of nano- $\mathrm{MgO}$ particle size on bactericidal action against Bacillus Subtilis, Var. Niger, Chin. Sci. Bull. 50, 514-519. DOI: 10.1360/04wb0075.

7. Climent, M.J., Corma, A., Iborra, S. \& Mifsud, M. (2007). $\mathrm{MgO}$ nanoparticle-based multifunctional catalysts in the cascade reaction allows the green synthesis of anti-inflammatory agents, J. Catal. 247, 223-230. DOI: 10.1016/j.jcat.2007.02.003.

8. Kumar, D., Reddy, V.B., Mishra, B.G., Rana, R.K., Nadagouda, M.N. \& Varma, R.S. (2007). Nanosized magnesium oxide as catalyst for the rapid and green synthesis of substituted 2-amino-2-chromenes, Tetrahedron 63, 3093-3097. DOI: 10.1016/j.tet.2007.02.019.

9. Seifi, M. \& Sheibani, H. (2008). High surface area $\mathrm{MgO}$ as a highly effective heterogeneous base catalyst for three-component synthesis of tetrahydrobenzopyran and 3,4-dihydropyrano[c]chromene derivatives in aqueous media, Catal. Lett. 126, 275-279. DOI: 10.1007/s1056-008-9603-5.

10. Polshettiwar, V., Baruwati, B. \& Varma, R.S. (2009). Selfassembly of metal oxides into three-dimensional nanostructures: Synthesis and application in catalysis, ACS Nano 3, 728-736. DOI: $10.1021 / \mathrm{nn} 800903 \mathrm{p}$.

11. Coluccia, S. \& Tench, A.J. (1980). Proceedings of the $7^{\text {th }}$ International Congress on Catalysis, Tokyo, 1157.

12. Alejski, K., Emmons, M., Lukosek, M. \& Miesiąc, I. (2010). Oxyethylation of fatty acid methyl esters using heterogeneous catalyst. Process modeling and experimental evaluation, Inż. Aparatura Chem. 49, 17-18 (in Polish).

13. Hreczuch, W. \& Szymanowski, J. (2007). Sposób oksyetylenowania estrów, Polish patent 194888.

14. Hama, I., Sasamoto, H. \& Okamoto, T. (1997). Effects of ethoxylate structure on surfactant properties of ethoxylated fatty methyl esters, Am. Oil Chem. Soc. 74, 823-827. DOI: 10.1007/s11746-997-0225-7.

15. Aramendía, M.A., Borau, V., Jiménez, C., Marinas, J.M., Ruiz, J.R. \& Urbano, F.J. (2003). Influence of the preparation method on the structural and surface properties of various magnesium oxides and their catalytic activity in the Meerwein-Ponndorf-Verley reaction, Appl. Catal. A: General 244, 207-215. DOI: 10.1016/S0926-860X(02)00213-2.

16. Gulková, D., Šolcová, O. \& Zdražil, M. (2004). Preparation of $\mathrm{MgO}$ catalytic support in shaped mesoporous high surface area form, Micropor. Mesopor. Mat. 76, 137-149. DOI: 10.1016/j.micromeso.2004.07.039.

17. Raths, H.C., Breuer, W., Friedrich, K. \& Hermann, K. (1994). Use of hydrophobized hydrotalcites as catalysts for ethoxylation or propoxylation, US patent 5292910.

18. Wolf, G., Burkhart, B., Lauth, G., Trapp, H. \& Oftring, A. (1998). Preparation of alkoxylation products in the presence of mixed hydroxides modified with additives, US patent 5741947.

19. Breuer, W. \& Raths, H.C. (1994). Hydrophobicized double layer hydroxide compounds, US patent 5326891.

20. Okamoto, T., Uemura, S. \& Hama, I. (2003). Alkoxylation catalyst and method for producing the same, and method for producing alkylene oxide adduct using the catalyst, US patent 6504061 .

21. Wang, B.H., Zhang, W.B., Zhang, W., Yu, C.Y., Wang, G., Huang, L.X. \& Mujumdar, A.S. (2007). Influence of drying processes on agglomeration and grain diameters of magnesium oxide nanoparticles, Dry. Technol. 25, 715-721. DOI: 10.1080/07373930701291108.

22. Yun, L., Wang, B.H., Jing, D., Lv, X., Yu, C.Y., Wang, G., Huang, L.X. \& Mujumdar, A.S. (2009). Drying kinetics of magnesium hydroxide of different morphological micro nanostructures, Dry. Technol. 27, 523-528. DOI: 10.1080/07373930802715252.

23. Melgunov, M.S., Fenelonov, V.B., Melgunova, E.A., Bedilo, A.F.K. \& Klaubunde, J. (2003). Textural changes during topochemical decomposition of nanocrystalline $\mathrm{Mg}(\mathrm{OH})_{2}$ to MgO, J. Phys. Chem. 107, 2427-2434. DOI: 10.1021/jp021474i.

24. Pilarska, A., Markiewicz, E., Ciesielczyk, F. \& Jesionowski, T. (2011). The influence of spray drying on the dispersive and 
physicochemical properties of magnesium oxide, Dry. Technol. 29, 1210-1218. DOI: 10.1080/07373937.2011.579698.

25. Alvarado, E., Torres-Martinez, L.M., Fuentes, A.F. \& Quintana, P. (2000). Preparation and characterization of $\mathrm{MgO}$ powders obtained from different magnesium salts and the mineral dolomite, Polyhedron 19 (2000) 2345-2351. DOI: 10.1016/S0277-5387(00)00570-2.

26. Hattori, H. (1995). Heterogeneous basic catalysis, Chem. Rev. 95, 537-558.

27. Pilarska, A., Paukszta, D., Ciesielczyk, F. \& Jesionowski, T. (2010). Physico-chemical and dispersive characterisation of magnesium oxides precipitated from the $\mathrm{Mg}\left(\mathrm{NO}_{3}\right)_{2}$ and $\mathrm{MgSO}_{4}$ solutions, Polish J. Chem. Tech. 12, 52-56. DOI: 10.2478/ v10026-010-0018-x.

28. Pilarska, A., Wysokowski, M., Markiewicz, E. \& Jesionowski, T. (2013). Synthesis of magnesium hydroxide and its calcinates by precipitation method with the use of magnesium sulfate and poly(ethylene glycols), Powder Technol. 235, 148-157. DOI: $10.1016 /$ j.powtec.2012.10.008.

29. Białowąs, E. \& Szymanowski, J. (2004). Catalysts for oxyethylation of alcohols and fatty acid methyl esters, Ind. Eng. Chem. Res. 43, 6267-6280. DOI: 10.1021/ie049898h.

30. Alejski, K., Białowąs, E., Hreczuch, W., Trathnigg, B. \& Szymanowski, J. (2003). Oxyethylation of fatty acid methyl esters. Molar ratio and temperature effects. Pressure drop modelling, Ind. Eng. Chem. Res. 42, 2924-2933. DOI: 10.1021/ ie020471p.

31. Hreczuch, W. \& Szymanowski, J. (1996). Synthesis of surfactants with narrow - range distribution of the polyoxyethylene chain, J. Am. Oil. Chem. Soc. 73, 73-78. DOI: 10.1007/ BF02523451.

32. Kim, D., Huang, Ch., Lee, H., Han, I. \& Kang, S. (2003). Hydrotalcite-type catalysts for narrow-range oxyethylation of 1-dodecanol using ethyleneoxide, Appl. Catal. A: General 249 229-240. DOI: 10.1016/S0926-860X(03)00297-7. 